MATEC Web of Conferences 53, 01029 (2016)

DOI: $10.1051 /$ matecconf/20165301029

(C) Owned by the authors, published by EDP Sciences, 2016

\title{
The Information Technology Project
}

\author{
Andrei Smirnov ${ }^{1, a}$ \\ ${ }^{1}$ St. Petersburg State University of Architecture and Civil Engineering, 2-Krasnoarmejskaja, 4, Saint-Petersburg, \\ 190005, Russia
}

\begin{abstract}
The author raises the question of suitable use of different software in construction. Currently, there are several design techniques using computer technology. The various stages of the project require their parameters and software settings. Comparison of programs is fundamental in this work. The author also raises the question of the unification of all the software and the possible establishment of an absolute tool for the design in the future.
\end{abstract}

\section{Introduction}

All data modeling programs may be divided into two big groups: CAD (Computer-Aided Design) and BIM (Building Information Modeling). The first one is based on drawings, preparing, special standards application and software management and development. The second group of data modeling programs uses another way. BIM-software is used for full model making [1]. Ready model is very useful in each stage of construction and building: project, erection, maintenance, engineers' cooperation, etc.

BIM-prepared project presents structure in realistic conditions. The model considers all stresses and deformations of the structure, the effect of different parts of the building to each other and allows designing engineering systems with the building.

Nowadays there is a big amount of proposed BIM-software in the world. They are divided into 6 groups: architecture, sustainability, structures, MEP (Mechanical, Electrical, and Plumbing), construction and facility management programs. The most popular in the world are ArchiCAD and Revit. There are popular software in different regions, such as Nemetschek in Germany or Tekla in Finland [2].

Most of design and building companies cooperate, and there is a problem to choose the one program for joint working. There are a lot of reasons to use certain program: habit, personnel training, different agreements, etc. In other words there no absolute program used by all building industry members.

3D-visualization simplifies the understanding of the project by all interested parties, as well as reduces the risk of making mistakes during installation. However, even $85 \%$ of engineers in Europe still prefer to use a 2D-program. Partly this is explained by the fact that the standards for the documentation are created under this format. A legal document recognized as a traditional drawing and expensive $3 \mathrm{D}$-model is a welcome addition to the status of the project. And there are no special

\footnotetext{
${ }^{a}$ Corresponding author: andrewsmirnov@inbox.ru
} 
laws about mandatory use of specific software. In addition, not all allied partners for the development and equipment suppliers are willing to receive information in the form of 3D-models [3].

Thus, the choice of software begets a problem in cooperation between building industry members. The vantage of $2 \mathrm{D}$ works is the reason of slow development and promotion of $3 \mathrm{D}$ technologies in building design. Probably the absolute program will be the decision of these problems.

The first stage of each project is an architectural design. The architect has to explain his own idea accessibly and technically correct. Also the final project has to be applicable for fellow engineers' and builders' working. CAD-models are very useful, but other members of building process have to have imagination for full project understanding. By the way, CAD-model may be in 3D. But BIM-models allow understanding the idea very graphically. And further working with this model are more comfortable and effectively because of import and cooperation abilities.

Thus, to construct the base architectural clear need to choose suitable software. Possibly select multiple criteria such as: the speed of the proposed instruments, the possibility of importing into other programs, library facilities and so on. As a global provider of software spectrum is important to choose taking into account the specific characteristics of each company and the particular specialist.

\section{CAD-software: AutoCAD and SketchUp}

The absolute market leader for the design of the proposed program is AutoCAD. It is safe to assume that about $90 \%$ of the world's construction industry uses this software. The remaining $10 \%$ comes from similar programs, such as nanoCAD or DraftSight [4]. Analogous programs are usually offered for free or much cheaper than AutoCAD. Often, however, the functionality is much lower, and export opportunities are limited at best, IFC-format (Industry Foundation Classes), and sometimes nonexistent [8].

AutoCAD offers a wide range of intuitive tools for creating drawings. All manner of plugins allow to automatically producing documentation to the required standards.

Newer versions of AutoCAD can support 3D-modeling. Creators from Autodesk are developing new technologies to accelerate the process [4].

Therefore, skill in AutoCAD is a prerequisite of successful work of the designer in our time. This program became the absolute software in the CAD-design, which is so lacking in BIM. All the necessary legislation and project drawings, specifications and cost estimates may be prepared using AutoCAD.

However, there are drawbacks. Despite extensive export opportunities in other software AutoCAD's formats (including IFC) are not supported by the majority of known visualization software. In other words, for the manufacture of the classic model for 3D-presentations AutoCAD is insufficient. It is possible to use a secondary program such as Revit or SketchUp to solve this problem.

Also, because AutoCAD is the CAD-software, it cannot edit user in the case of engineering error or offer the best solutions for a particular design.

SketchUp is a very progressive software design. Simple intuitive operation allows obtaining 3Dmodels of any complexity. It is widely used not only in construction but also in the production of furniture and interior planning. The great advantage of SketchUp is a huge library of ready components, where possible to find everything from small interior items and household appliances to aircraft and the world's interest. The user can create a project of any configuration with wider surroundings. The time spent on the production of realistic 3D-model via SketchUp is minimal [5].

However, it is advisable to use SketchUp in the initial stages of design: explanation of ideas, presentation, and marketing. This program does not manufacture finished drawings, sections, and plans. It is possible to estimate the volume of work required, compared with the existing facilities, but own experience and third-party software using. Also SketchUp cannot correct any errors or to offer solutions of design problems.

Own SketchUp graphics are "cartoonish"; not the quality for a presentation. But SketchUp format files are supported by most visualization programs. For example, SketchUp-Lumion ligament model 
allows producing the highest quality photorealistic render. It is also possible to make a video or panorama.

Both programs have the actual drawing tools: lines, shapes, polylines, etc; auxiliary editing copy, reflection, "squeezing" in 3D, zoom, etc. In other words, the user manually makes the necessary structural elements.

Thus, the CAD-software is an indispensable tool for the manufacture of the design documentation, calculation and presentation. However, the functionality of this technology is quite low as compared to BIM. In fact, a large number of works which can be performed automatically, is done by hand [8]. When producing 3D-model, the user should automatically receive all the necessary sections, plans and specifications, but it is not available for the CAD-software.

\section{BIM-software: ArchiCAD and Revit}

Undisputed leaders in the BIM-technologies are two competitors: ArchiCAD and Revit. Similar in functionality, they, however, have different audiences [8].

ArchiCAD was established in 1984 under the name of the company by Graphisoft Radar $\mathrm{CH}$, working only with the water supply. The latest version is ArchiCAD 18 and it is already a complete solution for the design of buildings and structures. Despite the name, containing the product range $\mathrm{CAD}$, this program is a classic example of BIM-software. The fact that this name was given before specific wording BIM, and in order to maintain the audience Graphisoft members decided to keep the brand ArchiCAD [6].

Revit is a product of Autodesk, the largest provider of software for architects, engineers and designers. For example, a well-known AutoCAD - is also a product of this company. And Revit was created specifically as a competitor for ArchiCAD. The first version was introduced in 2000 in the form of three programs: Revit Structure, for engineering calculations; Revit Architecture, for architects; and MEP-version for the design of communications structures. But in 2013, all three branches have been merged into one program as a result received a powerful tool conceived to fully integrated design of all building systems [7].

These two programs use similar construction elements that have counterparts in the real world: walls, columns, windows. To create shells have special manual tools. This is one of the fundamental differences between the CAD-software. Binding system is based on the preliminary establishment of the grid axes and elevation plans, on the basis of which all objects are built. Also, both programs have intelligent systems that allow the user to adjust in the case of engineering error or offer more optimal solutions of structural problems [8].

According to the survey, ArchiCAD used by about $30 \%$ of active users. Revit's audience is about $25 \%$ [8]. The spread is small, linked, rather, to the fact that ArchiCAD was introduced to the market for a much longer time to collect specific targeted clientele. Revit, however, the number of users reduces the gap each year [2].

ArchiCAD and Revit are categorized BIM-software. Therefore, their use in stages from design to operation is quite appropriate. However, Revit has a much wider field of application. This program not only prepares the complete drawings of all building elements, but some specifications and sheets for further operation and even dismantle the building. Also, as has been said, Revit combines opportunities for all designers: structural engineers, MEP software, engineers, architects, and so on. ArchiCAD cannot yet boast full internal integration. It requires separate programs for different sections of the design.

A very important issue is the creation time of the project. Models of ArchiCAD and Revit are much more time consuming. Even the creation of the elementary project in the first stages of the design must require a fairly large amount of time for the placement of axes and elevations, installation of all design elements, further imaging process. Therefore, if the initial stages of the project requires only to explain ideas and presentations, ArchiCAD and Revit - not always the best choice [8].

Exporting abilities of Revit is much higher than that of ArchiCAD. For example, visualization programs Artlantis, Lumion and V-Ray work with Revit format files. There is also an export from 
AutoCAD. ArchiCAD in this plan falls behind. Artlantis has been specially created for it, with no problems exporting. But if the user wants to use the other software, then it is required to transfer finished ArchiCAD models in IFC-format, which is fraught with losses, bugs, time-consuming [1] [2] $[6,9-12]$.

Both programs have their own tools for visualization. Assign different texture layers model transforms the image into a realistic object. However, in comparison with similar methods render that offer Lumion or Artlantis, own visualization of ArchiCAD or Revit looks worse as they are simplified to the minimum necessary, so no settings of light and shade, reflection, reflections, transparency, global illumination, etc. For the presentation of the object, making of clips, panoramas and displays need to use third-party software [13-15].

Thus, these programs have their own advantages and disadvantages. The possible association of the experiments would create a product that is suitable for everyone $[16,17]$. This is what Autodesk is currently seeking by perfecting Revit each year to obtain new customers and consumers. At the same time Graphisoft is releasing a new version, that does not much change the functionality and flexibility of the software, but appeals to a closed circle of conservative admirers of the software, valuing stability and not spending time learning new techniques and technologies on a broad scale [18-21] .

\section{Conclusions}

Thus, it is possible to draw the following conclusions:

- In the various design stages require different indicators. To produce a model of the facility as soon as possible it is better to use CAD-software. If do not needed presentation-quality 3D-models to explain all the ideas and proposals, it is logical to use AutoCAD. But in case of the need for photorealistic images and objective indicators of exteriors and interiors of the building is better to use tools of SketchUp followed by visualizing.

- CAD-software can export to IFC-format and BIM. Such a course of action to accelerate the initial basic design with subsequent upgrades in complex project for further work during construction and operation. However, more time may be the cost of bringing objects from one program to the requirements of the other.

- In the case of the initial solutions for integrated project and construction work at several engineers or companies it is advisable to use a BIM-software. Parallel works of engineers of different specialties require the use of such technologies. BIM-program will take into account the impact of all the elements and structures of the building on each other.

However, the question remains about the absolute program, which will use the vast number of users, is still open. In the case of CAD-software the leader is AutoCAD, and already it is doubtful that any other product will be able to take its place. A possible candidate for the same position in BIMtechnology is Revit, which is developing rapidly.

Thus, at the moment of virtual design technology are in a stage of rapid development. New ideas emerge every year, and the degree of optimization are becoming higher and higher. So perhaps, in the future there will be introduced a mandatory design through modeling or predictive calculation with attendant checks and correcting.

\section{References}

1. B. Hardin, D. McCool, BIM and Construction Management: Proven Tools, Methods, and Workflows. $2^{\text {nd }}$ Edition (Indianapolis, 2015)

2. M. Hergunsel Benefits of building information modeling for construction managers and BIM based scheduling (Master's Thesis, Worcester, 2011) 
3. M. Day, AEC Magazine, 1(47), 16-19 (2013)

4. L. Allen AutoCAD Professional Tips and Technique (San-Rafael, 2014)

5. A. V. Petelin 3D-modyelirovaniye v SketchUp 2015 in 2 volumes (St. Petersburg, 2015)

6. N. I. Malova ArchiCAD 18 v primerah (St. Petersburg, 2015)

7. J. Vandezande, P. Read, E. Krygiel Autodesk Revit Architecture 2013: Autodesk Official Training Guide (San-Rafael, 2015)

8. A. V. Smirnov The comparison of the architectural design softwares (Bachelor's Thesis, Lappeenranta, 2015)

9. V.L. Kvint, V.V Okrepilov, Herald of the Russian Academy of Sciences, 84 (3), 188-200 (2014)

10. Z. Jakšic, D. Ladjinović, M. Trivunić, N. Harmati, N. Vatin, (2015) Procedia Engineering, 117 (1), 507-520 (2015)

11. K. Strelets, N. Vatin, (2015) Rocznik Ochrona Srodowiska, 17 (1), 104-112 (2015)

12. N. Harmati, Z. Jakšić, N. Vatin, (2015) Procedia Engineering, 117 (1), 791-799 (2015)

13. A. Milajić, D. Beljaković, D. Davidović, N. Vatin, V. Murgul, Procedia Engineering, 117, 916$923(2015)$

14. B. Stamatovic, R. Upadhyay, Procedia Engineering, 117 (1), 660-667 (2015)

15. Z.Popović, L. Lazarevic, N. Vatin, Procedia Engineering, 117 (1), 846-853 (2015)

16. M. Jevrić, M. Knežević, J. Kalezić, N. Kopitović-Vuković, I. Cipranić, Tehnicki Vjesnik, 21 (4), 873-879 (2014)

17. M. Lazarevska, M. Knežević, M. Cvetkovska, A. Trombeva-Gavriloska, Tehnicki Vjesnik, 21 (6), 1353-1359 (2014)

18. N. Pavličić, M. Perazić, D. Durić-Jocić, M. Knežević, Journal of Applied Engineering Science, 12 (1), 11-18 (2014)

19. B. Melović, S. Mitrović, A. Djokaj, N. Vatin, Procedia Engineering, 117 (1), 807-812 (2015)

20. B. Kovačič, R. Kamnik, A. Štrukelj, N. Vatin, Procedia Engineering, 117 (1), 800-806 (2015)

21. S. Rutešić, J. Ćetković, M. Knežević, M. Žarcković, N. Vatin, Procedia Engineering, 117 (1), $642-$ $650(2015)$ 